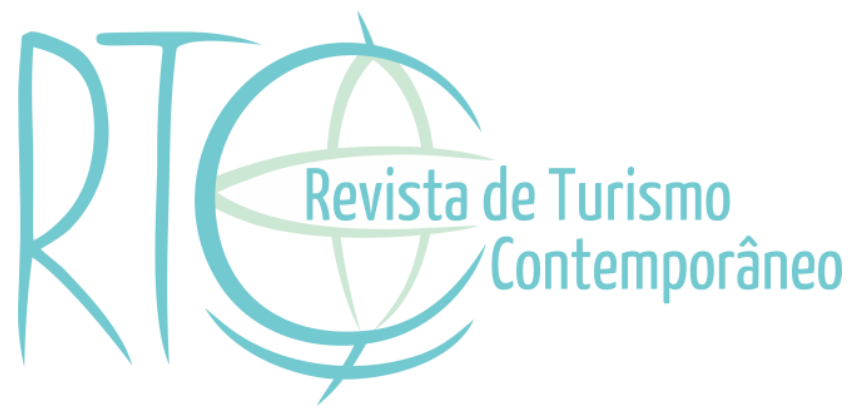

\title{
A casa da rua São Francisco: um caso folkcomunicacional do turismo de assombrações em Diamantina - MG
}

\author{
"A casa da rua São Francisco": a folkcommunicational case \\ of haunted tourism in Diamantina - MG
}

\section{Alan Nascimento}

Professor Associado I do curso de Turismo e do mestrado em Estudos Rurais da Universidade Federal dos Vales do Jequitinhonha e Mucuri - UFVJM, Diamantina/MG, Brasil

E-mail: alan.faber@ufvjm.edu.br

\section{Jéssica Sousa de Oliveira}

Graduanda do curso de Turismo da Universidade Federal dos Vales do Jequitinhonha e Mucuri - UFVJM, Diamantina/MG, Brasil

E-mail: jessicasousaoliveira05@gmail.com 


\section{RESUMO}

O Turismo de assombrações é um segmento do chamado turismo histórico-cultural. O processo de construção desse tipo de produto turístico suscita a questão de como é que os elementos próprios do mundo da tradição têm atraído as audiências modernas, turistas e viajantes. $\mathrm{Na}$ tentativa de oferecer uma resposta, este trabalho explora, conceitual e empiricamente, a turistificação de histórias de assombrações com base na noção de folkcomunicação. As técnicas de pesquisa adotadas pela investigação compreendem revisão bibliográfica e observação participante no city tour "Lendas do Tijuco", realizado pela agência de turismo "Minhas Gerais", na cidade de Diamantina-MG. Como resultado da investigação, sustenta-se que o turismo de assombrações se baseia num processo em que elementos da tradição local se mesclam com estéticas transnacionais, oriundas do cinema, da cultura pop do terror, das indústrias culturais, em geral, o que transforma almas penadas, a violência contra o escravo, a cultura funerária colonial, entre outras referências da morte de outrora, numa experiência turística, paradoxalmente, reconhecida e atual.

Palavras-chave: Meios de Comunicação. Turismo Histórico. Folclore.

\section{ABSTRACT}

Haunted tourism is a segment of so-called historical-cultural tourism. The process of building this type of tourism product raises the question of how the elements of the world of tradition have attracted modern audiences, tourists and travelers. In an attempt to offer an answer, this work explores, conceptually and empirically, the touristification of ghost stories based on the notion of folkcommunication. The research techniques adopted by the investigation include bibliographic review and participant observation in the city tour "Lendas do Tijuco", carried out by the tourism agency "Minhas Gerais", in the city of Diamantina-MG. As a result of the investigation, it is argued that haunted tourism is based on a process in which elements of the local tradition blend with transnational aesthetics, originating from the cinema, the pop culture of terror, the cultural industries, which transforms souls punishments, violence against the slave, the colonial funerary culture, among other ancient death references, in a touristic experience, paradoxically, recognized and current.

Keywords: Media. Heritage Tourism. Folklore. 


\section{INTRODUÇÃO}

De Minas, tudo é possível. Viram como é de lá que mais se noticiam as coisas sensacionais ou esdrúxulas, os fenômenos? O diabo aparece regularmente, homens e mulheres mudam anatomicamente de sexo, ocorrem terremotos, trombas d'água, enchentes monstras, corridas de terreno, enormes ravinamentos que desabam serras, aparições meteóricas, tudo o que aberra e espanta.

Guimarães Rosa ${ }^{1}$

Se fosse possível viajar ao Brasil dos princípios do século $\mathrm{XX}$, a fim de tomarmos ciência sobre qual era a representação da cidade que nutria o imaginário de nossos antepassados, é provável que o experimento causasse grande surpresa - menos por aquilo que, à época, o urbano prometia, e mais pelo que o rural, décadas depois, passaria a suscitar nas pessoas.

Naqueles tempos, o urbano representava tudo o que o mundo da tradição sonegava do futuro do país: o progresso econômico e social, o desenvolvimento tecnológico, a democracia. Assim, enquanto o imaginário em torno do rural evocava o atraso de um presente a ser superado, a cidade e seus objetos-símbolos, dos arranha-céus aos automóveis, prometiam o futuro para a jovem nação que começava a se modernizar.

Causa espanto, portanto, que, no curto espaço de um século, a imagem do rural, do tradicional, tenha se modificado da água para o vinho. E, assim, nos dias de hoje, o Brasil tradicional virou moda, e o rural e os signos dele nas cidades e nas metrópoles se tornaram cult - tudo isso num país em que, sublinhe-se, a população, segundo as estatísticas, desde a década de 1960, é majoritariamente urbana.

Uma das expressões mais emblemáticas disso é a transformação, pelas cidades do país afora, de histórias de assombrações e visagens em produtos turísticos. Ainda que isso não seja uma exclusividade nativa, haja vista roteiros internacionalmente famosos baseados nesse tipo de folclore, não deixa de ser curioso o fato de que, independentemente do tamanho ou grau de urbanização, não são poucas as cidades brasileiras que têm procurado atrair visitantes por meio dessa modalidade de turismo histórico-cultural.

Nas duas principais capitais do país, por exemplo, na esteira dos projetos de "revitalização" dos seus respectivos centros históricos, o trade turístico tem explorado o desejo de experienciar o sobrenatural. Atualmente, na cidade de São Paulo, o "SP Haunted Tour" propõe uma excursão noturna a bordo de um ônibus que circula por construções do patrimônio histórico da cidade, como o Cemitério da Consolação, o Teatro Municipal e a Catedral da Sé. Na capital fluminense, por sua vez, há o "Tour Fantasma”, que promove um passeio guiado

\footnotetext{
${ }^{1}$ Trecho retirado do texto "Aí está Minas: a mineiridade" de Guimarães Rosa publicado em 1957. Recuperado de https://docplayer.com.br/11419642-Ai-esta-minas-a-mineiridade.html
} 
pelos prédios históricos da Biblioteca Nacional, do Museu Nacional das Belas Artes e pela Câmara dos Vereadores.

Já nas regiões norte e nordeste do país, o que não falta são roteiros turísticos dessa natureza. Note-se que as empresas turísticas da capital pernambucana promovem passeios inspirados em "Assombrações do Recife Velho", obra de nosso mestre de Apipucos, Gilberto Freire; ao passo que, na Amazônia, todo material folclórico que, nas décadas de 1920 e 1930, compuseram movimentos vanguardistas, tem sido ressignificado pelas indústrias culturais da região.

Em que pese a difusão por todo o território nacional, talvez seja no estado de Minas Gerais que a curiosidade urbano-metropolitana por assombrações e visagens tem sido explorada mais sistematicamente - em especial, nas cidades coloniais mineiras, nascidas, nos Setecentos, do garimpo do ouro e do diamante.

Tanto que, recentemente, a cidade de Sabará se autoproclamou a capital nacional das histórias de assombração. Em Mariana, por sua vez, a Associação de Caçadores de Assombração, a ACAM, ostenta um portfólio que reúne cerca de 40 histórias de fantasmas e almas penadas. E na vizinha Ouro Preto, há pouco tempo, a convite de emissoras locais, investigadores paranormais foram chamados para analisar dois misteriosos casos da cidade: o de um espírito que ronda um antigo casarão transformado em moradia estudantil, e o caso dos fantasmas escravos da Mina do Chico Rei (Cazetta, 2016; Martins, J. P., 2014).

Desnecessário dizer que o desenvolvimento e a disseminação dessa modalidade de produto turístico desafiam a pesquisa em turismo a investigar a forma como se opera a transformação de personagens próprios do mundo da tradição num atrativo contemporâneo para as indústrias culturais. No caso específico de Minas Gerais, chama a atenção o modo como o passado escravocrata minerador, folcloricamente habitado por tantas almas penadas, tem se transformado hoje num produto turístico da região.

$\mathrm{Na}$ expectativa de ser uma contribuição para entender tal processo, o objetivo deste estudo é investigar o city tour "Lendas do Tijuco", realizado no centro histórico da cidade de Diamantina. A hipótese da investigação é que esse produto turístico enseja uma forma de experiência que, se, por um lado, rompe com o cotidiano do turista, ao levá-lo a um contexto social e histórico diferente do seu; por outro, paradoxalmente, necessita de uma ambiência contemporânea que ele reconheça. 


\section{METODOLOGIA}

Esta investigação se caracteriza pela natureza qualitativa, descritiva e exploratória. Para explorar a hipótese da pesquisa, a investigação adota o conceito de folkcomunicação, entendido como uma forma de comunicação em que elementos tradicionais são ressignificados para se tornarem legíveis às audiências modernas (Beltrão, 1980; Melo, 2008).

À vista da temática, pode-se perguntar por que não se usou para análise a noção de dark tourism. Ocorre, no entanto, que a noção de dark tourism, tal como inicialmente proposta a partir dos trabalhos de Foley e Lennon (1996), e de Seaton (1996), e depois desenvolvida ao longo dos anos, não se aplica bem ao caso estudado. Tanto que num dos principais trabalhos, se não o principal, de revisão de pesquisas sobre o tema, o de Light (2017), pouco se discorre acerca do turismo de assombrações. Na literatura, o conceito de dark tourism está muito mais associado à visitação a espaços de morte e sofrimento (sítios de guerra e assassinatos, campos de concentração, cemitérios onde jazem celebridades etc.) do que propriamente com histórias de fantasmas, lendas urbanas, que são narrativas próprias do mundo da tradição e do folclore embora, eventualmente, seja até possível identificar similitudes entre o turismo de assombração e algumas modalidades da tipologia proposta por Stone (2006).

É verdade que a opção pela noção de folkcomunicação limita as referências bibliográficas utilizadas a autores nacionais e que não pertencem ao corpus teórico do campo de estudos do turismo; por outro lado, cumpre dizer que, por se tratar de uma iniciativa ainda muito pouco desenvolvida na área, este trabalho, metodologicamente, perfilha ao lado daquelas contribuições que buscam o desvendamento analítico, com base na experimentação de outros marcos conceituais, das novas e contemporâneas formas de viagens e passeios turísticos.

Com efeito, os dados bibliográficos foram extraídos por meio de buscas mais amplas, e não focadas na literatura do turismo, por meio do Google Acadêmico. Optou-se, especialmente, pela revisão de artigos científicos e teses, e dissertações acadêmicas sobre os temas da folkcomunicação e das assombrações. Secundariamente, foram utilizados trabalhos historiográficos, antropológicos, reportagens de jornais e revistas eletrônicas.

Além da revisão bibliográfica, outra técnica de pesquisa adotada foi a observação participante. A observação participante consistiu no acompanhamento em campo do city tour "Lendas do Tijuco". A coleta das histórias contadas durante esse passeio turístico foi realizada por meio de anotações em caderno de campo e posterior transcrição delas. Para fins analíticos, dentre as histórias coletadas, foi escolhida a história "A Casa Assombrada da Rua São Francisco". 


\section{REFERENCIAL TEÓRICO}

\subsection{A noção de Folkcomunicação e como as almas penadas viram fantasmas no cinema e no turismo}

Foi na década de 1960 que o conceito de folkcomunicação passou a ser elaborado por Luiz Beltrão de Andrade e Lima. Na época, o autor pretendia abrir uma nova área de pesquisa na teoria da comunicação, preocupada em desvendar a forma como os grupos populares recebiam aquilo que era transmitido pelos meios de comunicação de massa. Em essência, a proposta desafiava a ênfase em aspectos visíveis e formais da linguagem midiática, tidos como ininteligíveis para as audiências populares, uma vez que elas não compartilhavam a mesma estrutura comunicacional dos agentes emissores.

Tratava-se, portanto, de trazer à luz a dimensão propriamente folclórica da comunicação popular - leia-se, o ecossistema simbólico específico adotado no ato de se comunicar por cada grupo cultural ou comunidade local. Nesse sentido, o objetivo do folkcomunicador era conseguir ressignificar os códigos oriundos do mass media para o contexto vivencial do agente receptor - no caso as populações marginalizadas brasileiras, notadamente as de origem rural. Razão por que, para uma boa transmissão da mensagem, fazia-se necessário conhecer, antes da emissão do texto, o contexto comunicacional no qual o outro estava inserido - notadamente, num momento em que o governo militar da época mais "enformava" do que informava o povo.

Daí que, para Beltrão (1980, p. 28), a folkcomunicação é:

(...) por natureza e estrutura, um processo artesanal e horizontal, semelhante em essência aos tipos de comunicação interpessoal já que suas mensagens são elaboradas, codificadas e transmitidas em linguagens e canais familiares à audiência, por sua vez conhecida psicológica e vivencialmente pelo comunicador, ainda que dispersa.

Mais recentemente, os seguidores dessa proposta teórica ampliaram o raio de observação dos fenômenos folkcomunicacionais e passaram a explorar o movimento inverso dos polos da folkcomunicação - isto é, aquele que se move da cultura popular para os espaços das indústrias culturais (Melo, 2008).

Longe de ser uma questão ociosa, tal reversão implica uma novidade na maneira como se realiza a transmissão da cultura tradicional. Afinal, se no passado era sobretudo a comunicação oral que assegurava o sentido etimológico da palavra tradição - que vem da palavra latina traditio, cujo significado é aquilo que uma geração entrega a outra -; hoje a mídia também pode exercer esse papel, ao efetuar o trânsito simbólico entre os elementos de uma cultura e outra. 
É preciso dizer, entretanto, que, nesse processo de apropriação midiática dos bens populares, ocorrem sempre ressignificações. A bem da verdade, à luz dos desenvolvimentos da antropologia e dos estudos folclóricos, seria inapropriado considerar que o trânsito de elementos culturais, por quaisquer que sejam os meios, contemporâneos ou antigos, ocorresse por força da inércia - isto é, como se destituído de mediações e sem alterações tanto na forma quanto no conteúdo (Bertolli \& Guaraldo, 2006). Basta lembrar das Ipupiaras e Cobras negras, mitos indígenas inventariados por Câmara Cascudo, que "originalmente" matavam, ao passo que sua contraparte adaptada pelos colonizadores portugueses, a Iara, era sedutora e mandava beijos apaixonados. Em suma, enquanto o mito original matava, o adaptado amava (Cascudo, 2002).

Um exemplo paradigmático de uso da folkcomunicação pelas indústrias culturais são as refilmagens de filmes japoneses de horror pelo cinema de Hollywood. Nos originais japoneses, os filmes são baseados em mitos, lendas e peças teatrais da cultura popular nipônica. Tanto que a ambientação dos filmes é construída de forma que o suspense dure durante todo o tempo do filme, enquanto a figura da morte é representada de forma metafórica - de certo uma ressonância da cultura funerária japonesa é baseada no culto aos ancestrais, onde, mesmo depois de mortos, os entes queridos habitam as casas dos vivos.

Já nas versões hollywoodianas, em vez de uma narrativa mais linear, são utilizados efeitos especiais e sonoros, bem como closes rápidos, para se criar o chamado jump scare técnica cinematográfica da cultura pop do terror que consiste em provocar, por meio de uma mudança abrupta de imagem ou evento, aliada ao aumento do som, o susto repentino na plateia. Ademais, nas produções americanas, a morte é representada de forma mais explícita, na maioria das vezes despida de qualquer elemento ritualístico (Tanaka \& Falcão, 2017).

Em que pesem essas primeiras distinções, a principal diferença que marca os remakes está no personagem central das histórias, a saber: o fantasma. Nos filmes originais, os fantasmas japoneses se encaixam muito mal em esquemas maniqueístas. Não há fantasmas bons tampouco maus. Note-se que o fantasma de uma mulher, por exemplo, é sempre alguém sedento por uma reparação oriunda de uma violência passada. Desse modo, as noções de bem e mal são porosas “já que, ao final da trama, o fantasma pode ser visto como vítima da ação de alguém quando em vida, e o mocinho pode ser desmascarado como vilão" (Tanaka \& Falcão, 2017, n.p.).

Tal ambiguidade, porém, não é frequente nas refilmagens americanas. O fantasma made in America costuma ser a reencarnação do mal por ter sido uma pessoa má em vida. O resultado é que a questão da vingança perde espaço para a assombração ou a maldição. A esse propósito, não deixa de ser curioso que a própria figura do fantasma nesses filmes é construída com base em referências cinematográficas mundialmente consagradas - caso, por exemplo, do filme " $\mathrm{O}$ 
Chamado", refilmagem do original japonês "Ringu", em que a feição da menina-fantasma faz, claramente, alusão à protagonista do filme "O Exorcista".

Seria exagerado, no entanto, interpretar a questão em termos de homogeneidade cultural. É preciso concordar que o cinema de terror já percorreu um longo caminho desde o seu início. Com efeito, para sanar a monotonia existente e injetar algo de novo, os produtores cinematográficos de Hollywood passaram a buscar inspiração em produções até então não muito difundidas no ocidente (Tanaka \& Falcão, 2017).

Além do cinema, a indústria do turismo também parece usar recursos folkcomunicacionais, a fim de criar novos produtos turísticos - sobretudo para vertentes, modalidades e segmentos do turismo histórico-cultural. Nesse caso, o uso da folkcomunicação é uma forma não só de seduzir o turista para uma experiência que, de fato, esteja vinculada ao lugar, mas, sobretudo, um veículo de engajamento e participação das comunidades locais. E isso não tanto pelas possibilidades de renda e emprego que a atividade pode gerar, e, sim, por permitir que as mudanças causadas pelo turismo sejam apropriadas e interpretadas de acordo com a linguagem e a memória do lugar - tal como "uma lembrança que estava quase que adormecida, sobrevivendo nas frestas das conversas sertanejas e dos sussurros urbanos e que as contingências do presente fez despertar no contexto coletivo" (Rodrigues, 1999, p. 53).

A título de ilustração, vale mencionar o estudo original de Bertolli e Guaraldo (2006) sobre o município paulista de Dois Córregos. No caso, pelo menos desde os anos 2000, a administração municipal, a mídia e o trade turístico local têm explorado comercialmente o mito do Unhudo da Pedra Branca, personagem folclórico da cultura caipira da região do interior de São Paulo.

Protagonizado por um cadáver ressecado, de unhas grandes e que usa chapéu de palha e roupas esfarrapadas, essa visagem costuma assombrar todos aqueles que ousam roubar frutas e flores da mata da Pedra Branca. Assim, aproveitando-se da fama no imaginário popular, o Unhudo foi ressignificado, e o personagem mítico passou a ser uma espécie de protetor ecoturístico das trilhas, cachoeiras e córregos da região. Ato contínuo, o Unhudo hoje atrai a curiosidade de turistas e visitantes, mas vive assombrando os que desrespeitam a natureza.

Note-se que, no exemplo apresentando, a folkcomunicação hibridizou o tradicional com uma causa pós-moderna - a sustentabilidade e a defesa do meio ambiente. Importa lembrar que, no folclore brasileiro, o corpo seco de uma alma penada significa a existência de um pecado sem perdão divino, cujo castigo é ficar vagando, sem descanso, pelos lugares em que esteve em vida - no caso do Unhudo, o seu lugar de morada é justamente uma área de preservação 
ambiental que integra a APA de Corumbataí, Botucatu e Tejupá. Dito de outro modo, o processo de folkcomunicação não é arbitrário. Dentre as diversas assombrações do folclore regional paulista, escolhe-se justamente aquela que possui algum tipo de ancoragem (o fato de o Unhudo perambular por uma área de preservação ambiental e assombrar os que roubam as frutas do lugar) que possa ser ressignificada para uma causa contemporânea.

Ao fim e ao cabo, o resultado da iniciativa dois-correguense de folkcomunicação por meio do turismo de assombrações é que:

(...) houve uma inversão da valorização da cultura caipira; se desde a primeira metade do século passado a qualificação "caipira" foi redefinida como uma adjetivação estigmatizadora e negativa, contrapondo-se ao moderno, racional e eficaz supostamente representado pelo estilo de vida e pela cultura da capital dos paulistas, desde a última década o município voltou-se afoitamente para a valorização de seu passado rural e de suas tradições culturais como estratégia de resistência, defesa de sua identidade e promoção turística (Bertolli \& Guaraldo, 2006, p. 5-6).

À luz do exposto, desnecessário dizer a importância desse tipo de iniciativa notadamente, num país em que as leis possuem pouca aderência ao cotidiano de quem deve obedecê-las, posto que são feitas de cima para baixo, ao arrepio das crenças, costumes e hábitos da sua população: "somos um país onde a lei sempre significa o 'não pode' formal, capaz de tirar todos os prazeres e desmanchar todos os projetos e iniciativas" (Matta, 1997, p. 100). E isso não é menos verdadeiro para as legislações protetivas do patrimônio histórico e ambiental - cuja aplicação, contrariando seus próprios princípios, não raras vezes descaracteriza territórios culturais, usurpa direitos consuetudinários, exclui comunidades tradicionais.

É claro que não se quer aqui negar a importância das institucionalidades criadas para essas causas, tampouco desconsiderar a sua evolução ao longo da história. O fato é que a proteção patrimonial também passa, ou deveria passar, por âmbitos não-institucionais, informais, cotidianos, por assim dizer, próprios do domínio da imaginação popular onde o fantástico não é apenas uma realidade feérica, mas uma advertência, um recado.

Afinal, como explicar que há pouco, na virada do século, quando todos diziam que o mundo ia acabar, falava-se em Belém que a grande cobra que habita os subsolos da cidade acordaria e levaria consigo todos os belenenses para o fundo dos rios amazônicos? (Silva, 2014). Ou, mais recentemente, por que, após o rompimento da barragem da Samarco, na cidade de Mariana, a Mãe do Ouro, a tal da bola de fogo que atravessa a mata sem incendiá-la, começou a aparecer repetidas vezes por aquelas paragens, conforme contam os moradores? (Cazetta, 2016) E o que dizer das aparições nas frentes de expansão urbana e imobiliária de Belo Horizonte, caso do complexo de viadutos para a região da Pampulha? (Starling, 2002). 
Em razão do exposto, pode-se dizer que existe hoje um novo tradicional midiatizado, que combina os elementos da cultura de massa com elementos da cultura popular pré-televisiva. Nesse processo, o circo, a feira, a festa, o grotesco, as histórias de assombrações, enfim, tudo aquilo que restou do rural, acaba gerando novas celebridades do sobrenatural, a exemplo de monstros chupa-cabras, ETs de Varginha, vampiros-lobisomens, aventasmas (Bentes, 2005). O resultado é um produto folkcomunicacional sofisticado, oriundo da cultura popular, e que têm atraído cada vez mais a curiosidade de consumidores em todo o mundo, em consonância com os princípios do desenvolvimento e do turismo sustentável.

\section{ANÁLISE E DISCUSSÃO DOS RESULTADOS}

\subsection{Estudo de caso: "A Casa Assombrada da Rua São Francisco"}

O "Lendas do Tijuco" é um produto turístico realizado no centro histórico tombado da cidade mineira de Diamantina, que vem sendo comercializado desde o ano de 2015, pela agência e operadora turística local "Minhas Gerais". Geralmente, o passeio tem início na praça Dr. Juscelino Kubitschek, marco do centro histórico de Diamantina, sempre à noite (tanto nas madrugadas de sábado quanto durante a semana). O roteiro é feito a pé, em grupos de aproximadamente 20 pessoas e durante o qual são contadas cerca de 8 histórias, em diferentes pontos e lugares da região central da cidade. Na oportunidade em que se realizou a pesquisa de campo desta investigação, foram contadas as seguintes histórias: A árvore do Acayaca, A Casa Assombrada da Rua São Francisco, A Noiva da Igreja das Mercês, A Procissão dos Escravos, A Assombração da Casa da Chica, A Procissão dos Mortos da Igreja do Carmo, O Sino da Catedral e A República do Assombrado.

Do ponto de vista da criação do roteiro, as histórias contadas são resultado de trabalho de pesquisa da guia responsável pelo city tour. As histórias são colhidas da tradição oral da cidade, bem como em arquivos históricos locais, caso de jornais de época guardados na hemeroteca da Biblioteca Municipal Antônio Torres, ou em livros de memorialistas e memórias da região, a exemplo das obras de Felício dos Santos e Aires Mata Machado, e do diário de Helena Morley, publicado em "Minha vida de Menina",

\footnotetext{
${ }^{2}$ Importa esclarecer que o fato de algumas histórias figurarem em fontes históricas, isso não significa, contudo, que possuam uma origem específica e localizável. Decerto, muitas das histórias publicadas nos jornais da época foram coletadas da tradição oral e do imaginário popular diamantinense. De modo que a própria publicação implica ressignificações. Acrescente-se, ainda, que essas histórias apresentam similitudes (elementos invariáveis) com histórias de outras regiões mineiras. A investigação, por exemplo, constatou que histórias com o tema das procissões assombradas de escravos também se acham nas lendas das cidades de Mariana e Ouro Preto.
} 
Figura 1 - Folder do city tour "Lendas do Tijuco". Note-se que, no canto superior esquerdo, a ilustração de uma das histórias que compõem o roteiro faz alusão à imagem icônica do padre Merrin do filme O Exorcista

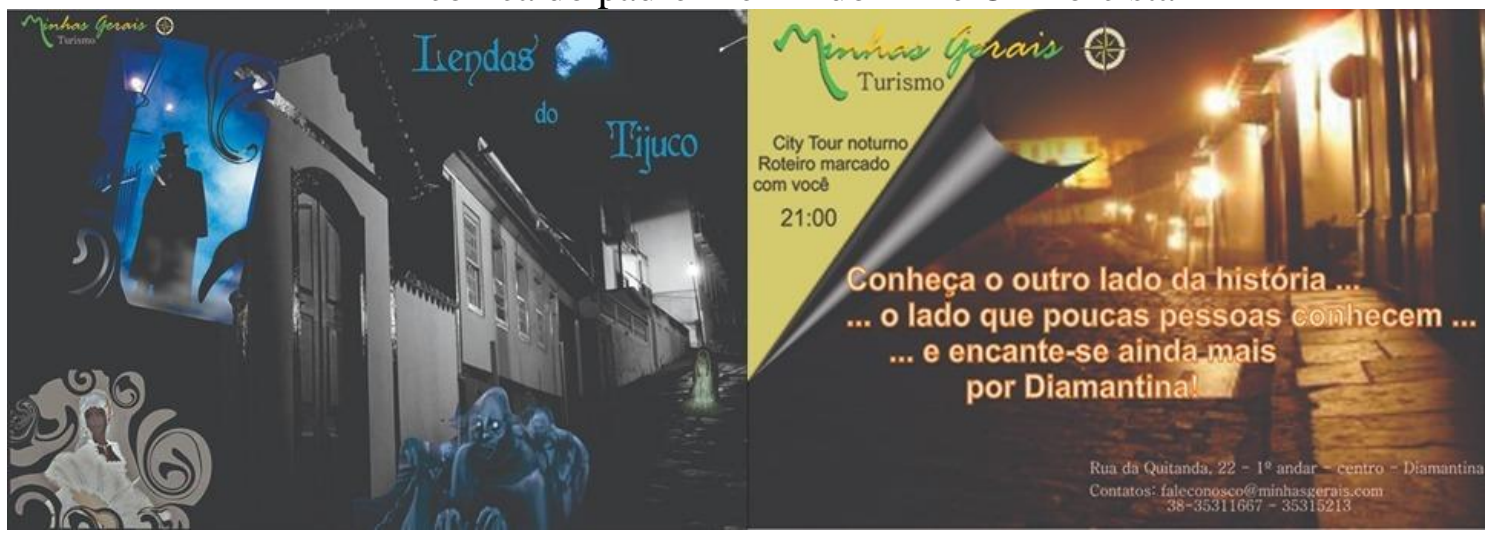

Fonte: Google Images, $2020^{3}$.

Das históricas contadas, escolheu-se, para a análise, “A Casa Assombrada da Rua São Francisco". Em primeiro lugar, porque a assombração habita um imóvel tombado, tanto pelo Instituto Nacional do Patrimônio Histórico e Artístico Nacional (IPHAN) quanto por fazer parte do conjunto arquitetônico reconhecido como Patrimônio da Humanidade pela UNESCO. E sobretudo porque a história é contada fazendo uma clara alusão a uma recente referência televisiva.

De imediato, deve-se dizer que, ao contrário de outras histórias em que foi possível localizar sua fonte histórica (a exemplo de "A árvore do Acayaca", presente nos diários e obras de Joaquim Felício dos Santos), no caso da história analisada, a investigação não encontrou a sua respectiva fonte, seja em jornais de época ou nos cadernos de memorialistas. Contudo, a ausência de compromisso historiográfico da história contada não significa perda de objetividade analítica. Afinal, o que se escrutina são os conteúdos tradicionais das narrativas e a maneira como eles são ressignificados para os turistas. Além do mais, lendas e histórias (estórias) têm sua razão de ser na verossimilhança com o contexto histórico e social ao qual elas pertencem, e não, sublinhe-se, com a representação factual do passado ${ }^{4}$.

Em síntese, a história “A Casa da Rua São Francisco" narra a vida de um rico fazendeiro, proprietário de muitas terras na região. Na casa onde morava, residiam ele, a esposa, os filhos e seus escravos. Conta-se que esse fazendeiro era um homem ganancioso e mau, devido à forma como tratava os cativos. Além de usá-los no garimpo de diamantes, também os obrigava a se reproduzir. Seu objetivo era vender escravos nascidos em sua fazenda para outros senhores da

\footnotetext{
${ }^{3}$ Recuperado de https://minhasgerais.com.br/diamantina-e-regiao/city-tour-de-lendas/

${ }^{4}$ Por não ter sido identificada a fonte histórica, optou-se por não expor fotos da casa assombrada, a fim de evitar qualquer estigmatização do imóvel - que inclusive estava à venda na época da pesquisa de campo. A esse propósito, nos Estados Unidos, em alguns dos seus estados, há leis que obrigam os corretores a informar o histórico do imóvel, como se ocorreu alguma tragédia em suas dependências ou se é habitado por fantasmas (Melo, 2014).
} 
região (o que era uma prática ilegal), de forma que mineradores e fazendeiros não precisassem comprar mão de obra no litoral.

Reza a lenda que, certa vez, o fazendeiro descobriu que uma equipe de padres inquisidores iria até sua fazenda, para averiguar a denúncia de que ele estaria reproduzindo escravos. Sabendo disso, ele começou a alimentar as crianças nascidas na fazenda com gordura de porco, para que elas morressem antes dos quatro anos por problemas cardíacos e, assim, os inquisidores não desconfiariam do seu negócio. Sua esposa, por sua vez, se compadecia do sofrimento dos escravos, por isso toda sexta-feira ela preparava um banquete e oferecia a eles. Contudo, seu marido sabotava a boa iniciativa da mulher colocando larvas na comida.

Não bastasse isso, o fazendeiro tinha, também, o costume de caçar os seus cativos. Em noite de lua cheia, ele pedia para que o capitão do mato pegasse uma criança na senzala e a soltasse pela propriedade. Munido de espingarda num cavalo encilhado, o malvado se divertia noite afora atrás da vítima para matá-la.

Perante tantas maldades, o castigo haveria de vir. Numa noite de caçadas, enquanto os moradores da casa se preparavam para dormir, a esposa e o capitão do mato ouviram gritos vindos do campo. Rapidamente, o capataz montou num cavalo e foi atrás do patrão acompanhado de um ajudante. Ao chegar ao campo, eles avistaram o fazendeiro desesperado com o corpo em chamas. Pegaram um cobertor e o enrolaram no fogueado. Quando retornaram à casa, a mulher do fazendeiro, que já tinha sido avisada do ocorrido, na companhia de um médico, preparou um quarto para que pudessem tratar das queimaduras do fazendeiro. Após gritar durante toda a noite, finalmente o homem adormeceu, e assim todos se retiraram para dormir também. No entanto, ao amanhecer, justo quando a esposa do fazendeiro vai até o quarto para conferir o estado do marido, inexplicavelmente, o corpo dele havia sumido, sem deixar nenhum rastro.

Acredita-se que, depois do desaparecimento do fazendeiro, a esposa permaneceu na casa até falecer - outrossim de maneira misteriosa. Os filhos, por sua vez, se mudaram para cidades grandes e procuraram cortar qualquer relação com o nome do pai. Desde então, as pessoas que residiram na casa, ou estiveram dentro dela por pouco tempo, começaram a contar que coisas estranhas tomavam lugar em suas dependências: objetos que caem sozinhos das prateleiras, vultos escuros que são vistos nos cantos das paredes, entre outros eventos sobrenaturais. Dando início, portanto, a história de assombração.

Para fins analíticos, é interessante notar que o período relatado na história remonta aos tempos da escravidão. Trata-se de um elemento comum das assombrações diamantinenses, qual 
seja: escravos que buscam, por causa de um passado colonial marcado pela violência contra o cativo, uma expiação.

De fato, mais do que qualquer outro ciclo econômico do Brasil escravagista, o do ouro foi conduzido a pau, ferro e fogo. Muito antes que a maquinaria dos estágios primeiros da industrialização, de equipamentos precários e primitivos, e desprovida de qualquer preocupação com a segurança do trabalho, rompesse com a concepção tradicional da "boa morte" - aquela que resulta do ciclo final da natureza, tal como a planta que frutifica e depois fenece, e que é precedida e acompanhada de todos os ritos funerários necessários (Martins, J. S., 2015) -, o garimpo tornou a vida banal, e a morte, horrenda.

Não por acaso ainda hoje se acredita que o atraso de algumas regiões mineiras, como é o caso do Vale do Jequitinhonha, onde está situada a cidade de Diamantina, é resultado de brutalidades do passado, todavia, não expiadas - como

se a pobreza que assola aquelas terras seria a consequência da lenta reparação moral e religiosa necessária para pacificar uma multidão de espíritos que perambulam por aqueles confins (Martins, M., 2008, p. 65).

Veja-se que, das oito histórias que compõem o roteiro turístico, com exceção de “A árvore do Acayaca" e da "República do Assombrado", seis delas se refiram a fantasmas-cativos. A esse propósito, vale assinalar que uma delas tem inclusive como personagem principal a ex-escrava Chica da Silva. Trata-se de um personagem histórico que é constantemente utilizado pelo marketing city de Diamantina, figurando nos mais diferentes produtos turísticos que formam a oferta turística municipal. É o caso da Vesperata ${ }^{5}$, principal produto turístico da cidade, na qual a história dessa personagem histórica que fora amante de um contratador de diamantes é ressignificada para se ligar a um imaginário-mundo, composto por casais universais, a exemplo de um Tristão e Isolda, ou de um Romeu e Julieta (Alves \& Nascimento, 2014).

Não é de estranhar, portanto, que, no folder de divulgação do city tour, ao lado da lua cheia, de fantasmas, entre outras referências hollywoodianas, apareça justamente a figura altiva da ex-escrava. Decerto, uma forma de assegurar, a um só tempo, autenticidade e familiaridade aos olhos do turista. O resultado dessa operação simbólica, concordando com Ortiz (2000, p. 134), é um espaço de rememoração onde presente, passado e futuro estão fundidos na

\footnotetext{
5 A Vesperata é um produto turístico local em que músicos se apresentam no alto das varandas de casarões históricos de Diamantina, enquanto o maestro, posicionado ao nível da rua (A rua da Quitanda), comanda a orquestra rodeado pelo público. Durante a apresentação, atores representando Chico da Silva e João Fernandes, o contratador de Diamantes, circulam entre os presentes para fotos.
} 
familiaridade de objetos-signos, e no qual "ao nos movimentarmos percebemos que nos encontramos no mesmo lugar".

Aprofundando em suas referências históricas, cumpre observar que a assombração da casa da Rua São Francisco é, em essência, uma alma penada. Em primeiro lugar, porque não é a justiça do rei ou da Igreja, em um tempo em que a cruz e a espada estavam unidas sob o regime do Padroado, que condena o infrator - vale lembrar que, à diferença do modelo escravagista norte-americano, de reprodução endógena, onde se permitiam as chamadas fazendas de escravos; no Brasil colonial, nas Minas setecentistas, tal prática era ilegal perante as ordenações do reino de Portugal. A reprodução da escravaria no Brasil ocorria, sobretudo, por meio dos negócios do tráfico negreiro (Marquese, 2006). Antes disso, é uma concepção de justiça popular que determina a condenação do proprietário de escravos. Aqui, o recado que vem dos mortos é bem claro. Ele vem de um adágio da sabedoria popular brasileira, qual seja: "a justiça tarda, mas não falha".

Em segundo lugar, porque a assombração dessa história é uma alma não redimida, a quem coube a condenação do corpo queimado, desfigurado e irreconhecível. Ora, na cultura funerária tradicional, a queima do corpo implica a dessacralização e a desumanização do "corpo santo". Trata-se de uma situação diametralmente oposta e, portanto, antípoda da chamada "boa morte" (Martins, J. S., 2015).

Dito de outro modo, o fim trágico e inexplicável do fazendeiro expressa, antes, uma punição coletiva. Pune-se não o ato ilegal, e, sim, a transgressão dos valores morais e emotivos de uma dada ordem tradicional - leia-se, os laços que mediam a relação entre o senhor e o escravo, porquanto, ideologicamente, ambos presos ao "nós comunitário" da casa grande e da senzala. A essa falta irredimível, a alma do falecido se encontra perdida, impossibilitada de atingir a salvação, o Reino dos céus. Restando a ela viver penando numa zona terrena liminar.

A despeito desses elementos pretéritos, o que mais chama a atenção na contação da história da "Casa Assombrada da Rua São Francisco" é a mescla do tradicional com referências midiáticas e televisivas contemporâneas. Referimo-nos a um episódio ocorrido durante as filmagens da minissérie "A Cura”, exibida pela rede Globo de televisão entre agosto e outubro de 2010.

Segundo a guia de turismo responsável pelo city tour, a casa da Rua São Francisco foi utilizada como cenário da moradia do personagem Dimas Bevilláqua, interpretado por Selton Mello. Conta-se que, em uma noite de filmagens, enquanto o ator se preparava para gravar uma cena no camarim improvisado nos quartos dos fundos da casa, ele sentiu alguém lhe tocar as 
costas e, pensando ser a senhora que sempre o acompanhava nos bastidores, começou a conversar com ela. Ao ouvir aquela a conversa, a tal senhora, que, na verdade, estava em outro cômodo, foi até o quarto e perguntou o que estava acontecendo. Foi quando Selton Melo olhou para trás e viu uma sombra negra o observando. Resultado: ele se assustou e saiu correndo da casa. Após esse acontecimento, diz-se que a equipe resolveu parar com as gravações na casa, voltando para os estúdios da Globo no Rio de Janeiro, de onde simulariam o cenário colonial da minissérie.

Figura 2 - Selton Mello em Diamantina durante as filmagens da minissérie "A Cura"

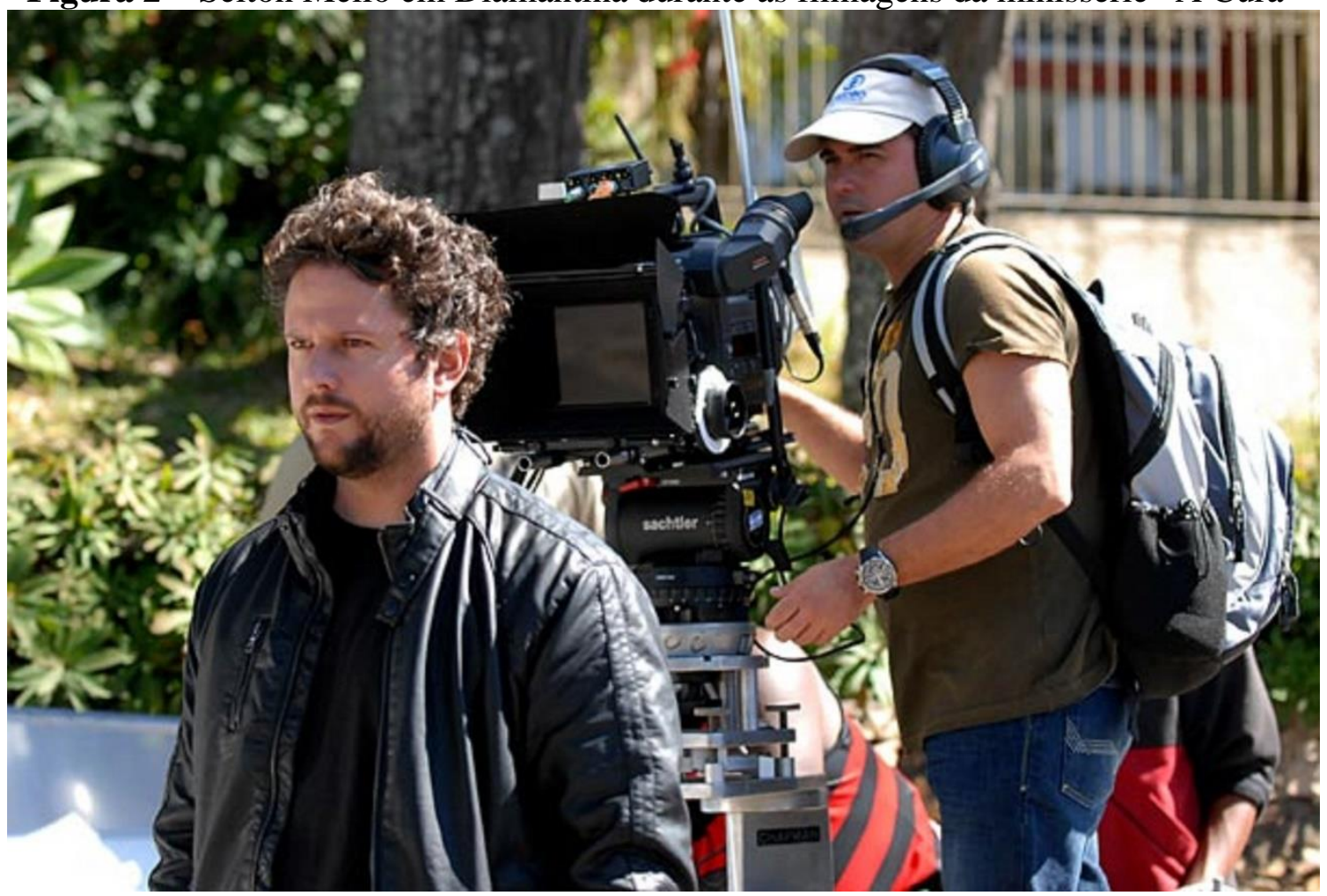

Fonte: Globo. Com, $2010^{6}$.

Independente se o episódio é factual ou não, uma vez que a investigação não encontrou nenhuma alusão a ele - a não ser uma notícia de que, à época das gravações, o elenco da minissérie experimentara episódios sobrenaturais (Paixão, 2010) -, o importante nos parece o uso de referências sígnicas, a fim de criar uma atmosfera de familiaridade com o aquilo que está sendo contado.

É curioso observar a homologia de temas e personagens entre a história contada da casa da Rua São Francisco e o enredo da minissérie. Em “A Cura”, o tema da história igualmente versa sobre questões próprias do mundo do além, como a questão da reencarnação e os poderes

\footnotetext{
${ }^{6}$ Recuperado de http://redeglobo.globo.com/novidades/series/noticia/2010/08/cura-confira-os-detalhes-dacaracterizacao-dos-personagens.html
} 
místicos da medicina espiritual. Outra semelhança é a figura do personagem Silvério, interpretado por Carmo Della Vecchia, cujo papel é justamente o de ser um minerador do século XVIII extremamente cruel com seus escravos - que, por sua vez, se reencarnará em Dimas Bevilláqua, que, da cidade grande, volta para sua terra natal para se ver curando as pessoas de Diamantina.

Ato contínuo, é como se as duas histórias se fundissem numa espécie de dejá vu. De modo que não seria exagerado supor que os elementos que compõem a história contada no city tour sejam oriundos, também, da minissérie. A esse propósito, vale lembrar que a alma penada que habita a casa age sobre o mundo dos vivos quebrando e movimentando objetos. Algo que está presente não apenas na ambiência da minissérie, cujo enredo tem clara inspiração no espiritismo, mas também nos próprios clichês do cinema de terror, onde os espíritos são tratados como seres barulhentos e telecinéticos.

O resultado dessa intertextualidade é a transformação da alma penada, que está na origem da história contada, no fantasma do produto turístico. Como já se disse, a alma penada é um espírito que busca uma reparação entre os vivos, para que possa, desse modo, deixar o limbo em que se encontra e adentrar no mundo dos mortos. Mais precisamente, a razão de ser da alma penada é simbólica, ritualística - é por meio do ritual que se redime a alma penada. O ritual pode ser uma missa rezada, o desvendamento do verdadeiro culpado do crime, ou, ainda, a justiça contra uma violência passada.

A representação do fantasma, por outro lado, tal como a conhecemos pelo senso comum e que é originada de múltiplas fontes, da literatura ao cinema, dos parques de diversão ao dark tourism, é alheia a qualquer forma de culto de livramento, porquanto a sua função primordial, frise-se, é a de assustar. Desse modo, o fantasma não se define pelo ritual, mas por um conjunto de fórmulas empregadas pelo gênero de terror, que mira, antes de tudo, o susto repentino:

Nossa cultura é uma cultura de almas penadas, de almas de outro mundo. Não é da nossa cultura, por exemplo, falar em fantasmas. O fantasma é importado de outras culturas, através da mídia. Vampiros não existem em nossa cultura. Nada disso é nosso. Tudo isso é importado, como o sanduíche do McDonalds, a Coca Cola, o Melhoral e tantas outras coisas mais (Martins, J. S., 2015, p. 144).

Por fim, há, ainda, mais um aspecto que reforça a natureza folkcomunicacional do “Lendas do Tijuco". É o caso do uso da folkcomunicação para criar uma situação social propícia ao efeito do horror. Sobre isso, tem razão Brite (2019, p. 49), apoiando-se em Tzevtan Todorov, ao concluir que, nos livros de terror, o fantástico depende essencialmente do real para acontecer. É que se faz necessário que o tempo-espaço da ficção seja uma espécie de duplicação do 
cotidiano, para que, uma vez criada a realidade familiar, reconhecida, ocorra o rompimento da normalidade e, assim, criar o susto terrificante: “ou seja, a realidade do leitor precisa estar bem delimitada na obra, para que, no momento em que o sobrenatural romper com essa realidade, o efeito do fantástico se faça de maneira exemplar".

À semelhança do que ocorre no mercado literário de horror, os fantasmas do turismo de assombrações dependem de expedientes de reconhecimento na formatação das histórias. Até porque, nesse segmento de turismo histórico-cultural, o atrativo está baseado em um tempo histórico e num espaço social que não é contemporâneo ao do turista.

Com efeito, para criar o cotidiano a ser quebrado, o guia de turismo se vale de recursos e técnicas que possam criar familiaridade para o turista - sem os quais, porém, a experiência do horror não se realizaria. A bem da verdade, é provável que o resultado da contação da história, na ausência de tais expedientes, resultaria num quadro cômico, e não terrificante - tal como ocorre, por exemplo, quando assistimos a um filme antigo de terror, caso do filme "Nosferatu", lançado em 1922, que, por causa do distanciamento temporal, em vez de provocar espanto, acabe, paradoxalmente, gerando para quem lhe assiste hoje risos e gargalhadas (Brite, 2019).

Daí, portanto, que o fantástico e o horror precisem sempre de novas formas e meios para representar personagens históricos e folclóricos (como lobisomens, vampiros, bruxas, mula sem cabeça, almas penadas etc.), e contextos antigos (Brite, 2019). Daí, enfim, a necessidade da folkcomunicação para a criação do produto turístico de assombrações.

\section{CONSIDERAÇÕES FINAIS}

Em “Ninguém Mata o Arco Íris" (Carvalho, 2019), relata-se uma entrevista que Juscelino Kubitschek supostamente teria dado a José Cândido Carvalho. Na oportunidade, o autor de "O Coronel e o Lobisomem" perguntou: "Presidente, como anda Diamantina em matéria de assombração?”. Ao que o ilustre diamantinense retorna às histórias de sua infância para, então, concluir: "que fantasma de castelo inglês, que nada! Assombração para o meu gosto só a do mineiro de Diamantina”.

Dos anos 1960 para os dias de hoje, muita coisa mudou no Brasil. Se a prédica presidencial era válida para as almas penadas que habitavam o dia-a-dia do homem do campo; para o brasileiro médio dos centros urbanos (e também para os seus congêneres no exterior), essa figura do catolicismo rústico, encontrada agora em momentos de lazer e férias, se confunde cada vez mais com o que se encontra nas telas digitais do nosso cotidiano.

$\mathrm{O}$ que se conclui é que, em vez de uma experiência substancialmente vernacular, o turismo de assombrações parece se explicar por um tipo de prática social que alcança o passado 
pelos signos produzidos pelos meios de comunicação, pelas indústrias culturais. Mais precisamente, no caso específico desta investigação, malgrado o uso de fontes históricas e referências do passado tradicional, não são raras, porém, as ocasiões em que, durante a contação das histórias, a guia de turismo se valha de signos da cultura de massas, ou mesmo de técnicas consagradas do cinema de terror, como o jump scare, para assustar os turistas.

Isso não significa, porém, que os elementos pretéritos não sejam importantes para a formatação desse produto turístico. Afinal, é por meio de referências ao passado que se alcança verossimilhança com aquilo que está sendo narrado, contado (o ciclo do ouro, o minerador e o escravo, o casario colonial etc.). O que, por sua vez, proporciona aos operadores do turismo, a um só tempo, conscientizar o turista, por meio de lições da sabedoria popular, por exemplo; bem como criar uma relação de memória afetiva entre a população local e os atrativos turísticos - na contramão, portanto, de modelos do turismo de massas.

Daí que, por meio dessa experiência turística, é possível, também, problematizar a questão racial das cidades coloniais mineiras, tão historicamente marcadas pela violência contra o negro na mineração - inclusive contra a criança negra, de que é exemplo o Saci Pererê, personagem do folclore brasileiro. Por conseguinte, o "Lendas do Tijuco" é, igualmente, um meio que leva a população mais pobre e periférica do município de Diamantina a se identificar simbólica e culturalmente com o patrimônio tombado do centro histórico da cidade. Além, é claro, malgrado os riscos de romantização - como por vezes ocorre com a figura da Chica da Silva -, de advogar contra a democracia racial brasileira - ainda mais para um setor que muito se valeu dessa mitificação ideológica para vender pacotes turísticos no país e no exterior.

Por fim, é preciso dizer que, embora o turismo de assombrações se utilize de um imaginário social criado pela mídia para ser legível aos olhos e ouvidos dos turistas, isso não autoriza a conclusão fácil de que se trata de uma prática social alienante e fetichizada. Muito longe disso. No fundamento dessa modalidade de produto turístico, eis não só o que a sociologia tem classificado como a ruralização das cidades e centros metropolitanos; mas, sobretudo, uma ideia de um folclore-mundo, entendido como algo dinâmico e não fossilizado, cada vez mais capaz, haja vista os atuais desenvolvimentos dos meios de comunicação, de incorporar temas e estéticas de diversas origens. Trata-se, portanto, de uma prática social baseada numa comunicação inovadora e sofisticada. 


\section{REFERÊNCIAS}

Alves, M. C., \& Nascimento, A. F. (2014). Controvérsias analíticas sobre a turistificação da musicalidade diamantinense: o caso das Vesperatas. Revista Cenario. 2(2), 123-139. Recuperado de https://doi.org/10.26512/revistacenario.v2i2.15201

Beltrão, L. (1980). Folkcomunicação: a comunicação dos marginalizados. São Paulo, SP: Cortez Editora.

Bentes, I. (2005). A pobreza criadora do folkmídia. Folha de São Paulo. Recuperado de: https://www1.folha.uol.com.br/fsp/mais/fs2301200502.htm

Bertolli, C., \& Guaraldo, T. S. B. (2006). Cultura local, Turismo e Identidade: a ressignificação dos mitos em Dois Córregos. Revista Científica Eletrônica Turismo, (4), 0116. Recuperado de:

http://faef.revista.inf.br/imagens_arquivos/arquivos_destaque/bvBAXNE34UxrtXd_2013-520-15-58-32.pdf

Brite, F. (2019). O fantasma em narrativas de horror da literatura brasileira. Dissertação de Mestrado. Mestrado em Literatura e Crítica Literária, Pontifícia Universidade Católica de São Paulo). Recuperado de: https://tede2.pucsp.br/handle/handle/22264

Carvalho, J. C. (2019). Ninguém mata o arco-íris: 35 retratos em 3x4. São Paulo, SP: Companhia das Letras.

Cascudo, L. C. (2002). Geografia dos Mitos Brasileiros. São Paulo, SP: Global.

Cazetta, J. (2016). As histórias que dão vida aos fantasmas na região de Mariana. Jornal $O$ Tempo. Recuperado de https://www.otempo.com.br/cidades/as-hist\%C3\%B3rias-qued\%C3\%A3o-vida-aos-fantasmas-na-regi\%C3\%A3o-de-mariana-1.1342921

Foley, M., \& Lennon, J.J (1996). JFK and dark tourism: a fascination with assassination. International Journal of Heritage Studies, 2(4), 198-211. Retrieved from https://www.tandfonline.com/doi/abs/10.1080/13527259608722175

Light, D. (2017). Progress in dark tourism and thanatourism research: an uneasy relationship with heritage tourism. Tourism Management, (61), 275-301. Retrieved from https://www.researchgate.net/publication/316473254_Progress_in_dark_tourism_and_thanato urism_research_An_uneasy_relationship_with_heritage_tourism

Matta, R. (1997). O que faz o Brasil, o Brasil? Rio de Janeiro, RJ: Rocco.

Melo, J. O. (2014). Justiça nos EUA discute se comprador deve ser informado sobre casa assombrada. Conjur. Recuperado de https://www.conjur.com.br/2014-nov-02/eua-discutemcomprador-informado-casa-assombrada

Marquese, R. B. (2006). A dinâmica da escravidão no Brasil: resistência, tráfico negreiro e alforrias, séculos XVII a XIX. Novos Estudos, (74), 107-123. Recuperado de http://dx.doi.org/10.1590/S0101-33002006000100007

Martins, J. P. (2014). Dois locais de Ouro Preto reservam histórias amedrontadas para as visitantes. Revista Encontro. Recuperado de https://www.revistaencontro.com.br/canal/atualidades/2014/05/dois-locais-de-ouro-pretoreservam-historias-assustadoras-para-os-visi.html 
Martins, J. S. (2015). Linchamentos: a justiça popular no Brasil. São Paulo, SP: Contexto.

Martins, M. L. (2008). Assombrações de Diamantina. Revista Leituras da História, (12), 56 66. Recuperado de http://historianovest.blogspot.com/2009/03/assombracoes-dediamantina.html

Melo, J. M. (2008). Mídia e Cultura popular: história, taxionomia e metodologia da Folkcomunicação. São Paulo, SP: Paulus.

Ortiz, R. (2000). Mundialização e Cultura. São Paulo, SP: Brasiliense.

Paixão, S. (2010). Elenco da série "A Cura" sente energia negativa da história. Portal Terra. Recuperado de https://www.terra.com.br/diversao/tv/elenco-da-serie-a-cura-sente-energianegativa-da-historia,b7fc02074d88a310VgnCLD200000bbcceb0aRCRD.html

Rodrigues, A. D. (1999). Comunicação e cultura: a experiência cultural na era da informação. Lisboa: Editorial Presença.

Seaton, A. V. (1996). Guided by the dark: from thanatopsis to thanatourism. International Journal of Heritage Studies, 2(4), 234-244. Retrieved from https://www.tandfonline.com/doi/abs/10.1080/13527259608722178?journalCode=rjhs20

Silva, G. (2014). Cultura Imaterial: mitos e lendas em Belém-PA. Revista Margem Interdisciplinar, 8(10), 169-185. Recuperado de http://dx.doi.org/10.18542/rmi.v8i10.2734

Starling, H. M. M. (2002). Fantasmas da Cidade Moderna. Revista Márgenes, 1(1), 66-75. Recuperado de http://www.periodicos.letras.ufmg.br/index.php/margens_margenes/article/view/10701/9450

Stone, P. (2006). A Dark Tourism Spectrum: towards a typology of death and macabre related tourist sites, attractions and exhibitions. Tourism: An Interdisciplinary International Journal, 54(2), 145-160. Retrieved from http://clok.uclan.ac.uk/27720/1/27720\%20fulltext_stamped.pdf

Tanaka, M., Falcão, F. (2017). A Construção do Medo no Cinema Japonês: caso Ringu, de Hideo Nakata. Revista Científica Multidisciplinar Núcleo do Conhecimento, 15, 112-120. Recuperado de https://www.nucleodoconhecimento.com.br/comunicacao/cinema-japones

FORMATO PARA CITAÇÃO DESTE ARTIGO

NASCIMENTO, A., \& OLIVEIRA, J. S. (2021). A casa da rua São Francisco: um caso folkcomunicacional do turismo de assombrações em Diamantina - MG. Revista de Turismo Contemporâneo, 9(3), 447-466. https://doi.org/10.21680/2357-8211.2021v9n3ID23971 